\title{
Differentiation of nicotinic and muscarinic anticholinergic effects on two schedules of reinforcement
}

\author{
CHARLES T. RASMUSSEN and HARRY H. AVIS \\ University of Nevada, Las Vegas, Nevada 89154
}

\begin{abstract}
An examination was made of the differential effects of the anticholinergic compounds, scopolamine and mecamylamine, on response inhibition under two different reinforcement schedules. Rats were trained on a multiple-schedule DRL-DRO. Each subject was then run under each of six different drug-dose combinations. All dose levels of both scopolamine and mecamylamine had significant disruptive effects on responding during the DRO schedule when compared to control injections of saline. Only high dose levels of scopolamine tended to disrupt responding during the DRL schedule. The peripheral action of methyl scopolamine and hexamethonium, on the other hand, had no measurable effect.
\end{abstract}

Considerable evidence exists to support the hypothesis that cholinergic receptors in the central nervous system may be differentiated into two types, muscarinic and nicotinic. Support comes from electrophysiological studies (Domino, 1968; Domino \& Yamamoto, 1965; Kawamura \& Domino, 1969), studies employing electrophoretic techniques (Barker, Crayton, \& Nicoll, 1971; Curtis \& Crawford, 1969), and behavioral studies (e.g., Avis \& Pert, 1974; Pert \& Avis, 1974; Schecter \& Rosecranz, 1971, 1976), as well as from studies involving direct application of cholinergic compounds into the brain (Armitage \& Hall, 1967; Brezenofi \& Wirecki, 1970; Stein \& Seifter, 1962).

Studies which assess behavioral effects of blockade of cholinergic receptors by antinicotinic and antimuscarinic compounds indicate that some behaviors may be differentially mediated by muscarinic and nicotinic cholinergic substances. Acquisition of two-way avoidance (Bignami, Amarico, Frontale, \& Rosic, 1971; Oliverio, 1966, 1967; Suits \& Isaacson, 1968) and habituation (Avis \& Pert, 1974) seem to be affected by antimuscarinic but not antinicotinic compounds, while performance of passive avoidance (Bohdanecky \& Jarvik, 1967; Calhoun \& Grant, 1972; Chiappetta \& Jarvik, 1969; Dilts \& Berry, 1967; Glick \& Greenstein, 1972; Goldberg, Sledge, Hefner, \& Rabichaud, 1971), acquisition of one-way avoidance (Goldberg et al., 1971; Meyers, Roberts, Riciputi, \& Domino, 1964; Suits \& Isaacson, 1968), and acquisition of fear conditioning (Pert \& Avis, 1974) are affected by both antimuscarinic and antinicotinic compounds.

Carlton (1969) has proposed that response inhibition may be mediated by cholinergic receptor systems. The

This research was supported in part by the University Research Council, University of Nevada, Las Vegas. The paper is sponsored by Dr. R. D. Tarte, who takes full editorial responsibility for its contents. work of Meyer, Severson, and Thompson (1976) lends support to this proposal. The question remains as to whether this mediation, if it occurs, is primarily muscarinic or nicotinic. The research reported below attempts to determine whether schedules of reinforcement which may require the subject to inhibit previously reinforced responses are differentially affected by the antinicotinic and antimuscarinic cholinergic drugs, mecamylamine and scopolamine, respectively. The two schedules selected were differential reinforcement of low rates of responding on a 20-sec schedule (DRL-20) and differential reinforcement of other behaviors on a $20-\mathrm{sec}$ schedule (DRO-20). These were combined in a multiple-schedule DRL-DRO.

\section{METHOD}

Eight male Sprague-Dawley hooded rats served as subjects. They were housed individually for the duration of the experiment. The room where the subjects were housed was on a 12-h light/dark cycle. All subjects were maintained at $80 \%$ of body weight for the duration of the experiment (range, 184 to $236 \mathrm{~g}$ maintained weight).

A standard operant chamber (BRS/LVE 143-22) was placed inside an outer chamber. Associated programming equipment recorded responses in two bins for the DRL-20 schedule and in one bin for the DRO-20 schedule.

All subjects were initially trained on a 20 -sec DRL for five sessions of $1 \mathrm{~h}$ each. After this training the animals were switched to a multiple-schedule DRL-DRO. Each component (DRL or DRO) was of 5-min duration presented alternately, for a total session length of $30 \mathrm{~min}$. The DRL-20 component was signaled by the presence of the houselight, while the DRO-20 was signaled by the absence of the houselight. Each subject was run on the multiple-schedule DRL-DRO for 45 sessions before drug injections began.

All drugs were dissolved in normal saline at the start of the experiment and injected in a volume of $1 \mathrm{~cm}^{3} / \mathrm{kg}$. Scopolamine was administered at a dose of .5 (LoScop) and 1.0 (HiScop) $\mathrm{mg} / \mathrm{kg}$, mecamylamine at 15 (LoMec) and 30 (HiMec) $\mathrm{mg} / \mathrm{kg}$, methyl scopolamine (MeScop) at $1.0 \mathrm{mg} / \mathrm{kg}$, and hexamethonium (Hex) at $30 \mathrm{mg} / \mathrm{kg}$. These dosages were administered in a modified Latin square design so that every animal received all injec- 
tions. Injections of compounds were given at least three sessions apart. An injection of saline in a volume of $1 \mathrm{~cm}^{3} / \mathrm{kg}$ was given 1 day prior to the last four injections.

The quaternary ammonium ganglionic blocking agent, hexamethonium bromide, and the quaternary ammonium derivative, methoscopolamine bromide (methyl scopolamine), were included to control for the peripheral side effects of mecamylamine and scopolamine, respectively. These quaternary derivatives do not as readily pass into the CNS and consequently do not possess significant central effects.

The reinforcer used was sweetened condensed milk (concentration: one part Borden Eagle Brand sweetened condensed milk to two parts water). Milk was used because preliminary investigation showed that anticholinergic drugs produce a dry mouth, which reduces the number of food pellets consumed. However, anticholinergic drugs have no effect on the ingestion of sweetened condensed milk (Avis \& Pert, 1974; Berger \& Stein, 1969).

\section{RESULTS}

Only the high dose of scopolamine significantly increased responding during DRL-20 $(p<.05$, Walsh test, two-tailed). The high dose of scopolamine did not, however, change the number of reinforced responses; thus, the subjects increased the number of nonreinforced responses. This finding is supported by an examination of the "interresponse times per opportunity," or IRT/OP, a statistic that measures the probability of the subject making a response in any given time span. It is computed by dividing the number of responses in any given bin by the total number of responses less those in the preceding bin(s). The effect of scopolamine on responding during DRL-20 can be seen in Figure 1, which presents the data for a typical subject. As time from last response increases, the probability of the subject responding increases much more rapidly when in the scopolamine condition than in either the saline or methyl scopolamine condition.

In contrast to the effect on DRL-20, both doses of mecamylamine and both doses of scopolamine increased

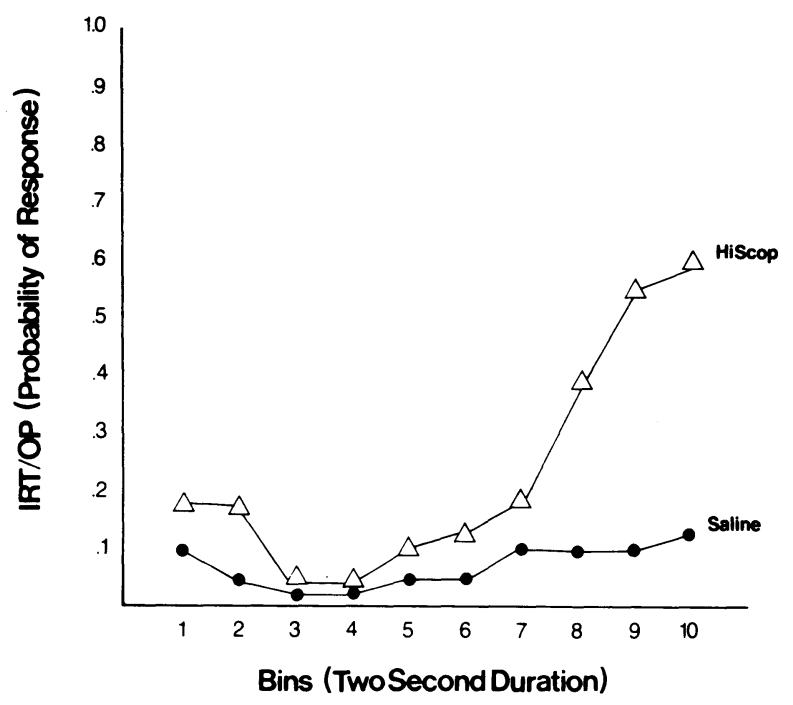

Figure 1. IRT/OP saline and HiScop conditions. responding on DRO-20 ( $p<.05$, two-tailed Walsh test), while hexamethonium and methyl scopolamine were without effect. Since programming equipment was not available to measure the distribution of responses during the DRO-20 component, no such analysis was possible.

\section{DISCUSSION}

The results indicate that centrally acting anticholinergic drugs differentially affect the two components of a DRL-DRO multiple schedule. The fact that methyl scopolamine and hexamethonium, the peripherally acting analogs of scopolamine and mecamylamine, respectively, were without effect suggest that the increase in responding is mediated centrally.

One explanation for the differential effect on the two schedules is that DRL is mediated by muscarinic and DRO by both muscarinic and nicotinic cholinergic fibers, suggesting the response inhibition in DRO differs from the response inhibition in DRL. Since the low dose of scopolamine was ineffective in altering DRL performance, an alternative hypothesis is that the doses of mecamylamine were not sufficient to alter DRL and that higher doses would be effective. Dosage equivalences are difficult to determine; however, $1.0 \mathrm{mg} / \mathrm{kg}$ of scopolamine is a relatively low dose, while $30 \mathrm{mg} / \mathrm{kg}$ is higher than was typically used in previous published studies. Preliminary studies indicated that some signs of behavioral toxicity occurred at $45 \mathrm{mg} / \mathrm{kg}$ of mecamylamine.

The data might also be explained by a task difficulty or, relatedly, a failure of stimulus control hypothesis. Ksir (1974) has shown, for example, that scopolamine disrupts difficult tasks more than simpler ones. Laties and Weiss (1966) have stated that drugs would have more effect on behavior under weaker stimulus control than under stronger stimulus control.

The task difficulty hypothesis seems untenable since it would require that DRO-20 be a more difficult task than DRL-20, a highly improbable occurrence. It is possible, however, that anticholinergics may disrupt stimulus control. That is, the subject may simply be unable to distinguish between the components of the multiple schedule. The median differences between control and drug were not large in the DRO-20 condition, suggesting that the subject may be able to use the delivery of a reinforcer noncontingent on responding as a stimulus cue. However, this hypothesis does not account for the lack of increase in responding during the DRL-20 component for all drugs except the high dose of scopolamine, nor does it account for the change in the distribution of IRT/OP in the high-dose scopolamine condition.

The results do indicate that pharmacological differentiation of two types of behavior which both require response inhibition is possible. Further research is required to assess the alternative hypotheses.

\section{REFERENCES}

Armitage, A. K., \& Hall, G. H. Further evidence relating to the mode of action of nicotine in the central nervous system. Nature, 1967, 214, 977-999.

Avis, H. H., \& PERT, A. A. A comparison of the effects of muscarinic and nicotinic anticholinergic drugs on habituation and fear conditioning in rats. Psychopharmacologia, 1974, 34, 209-222.

Barker, J. L., Crayton, J. W., \& Nicoll, R. A. Supraoptic neurosecretary cells: Adrenergic and cholinergic sensitivity. Science, 1971, 171, 208-210.

Berger, B. D., \& Stein, L. An analysis of the learning deficits produced by scopolamine. Psychopharmacologia, 1969. 14, 271-283.

Bignami, G., Amarico. L., Frontale, M., \& Rosic, N. Central cholinergic blockade and two-way avoidance 
acquisition: The role of response disinhibition. Physiology and Behavior, 1971, 7, 461-470.

BoHDANECKY, Z., \& JARvix, M. E. Impairment of one-trial passive avoidance learning in mice by scopolamine, scopolamine methylbromide, and physostigmine. International Journal of Neuropharmacology, 1967, 6, 217-222.

Brezenofi, H. E., \& Wirecki, T. S. The pharmacological specificity of muscarinic receptors in the posterior hypothalamus. Life Sciences, 1970, 9, 99-109.

Calmoun, W. H., \& Grant, M. J. Preinjection time of scopolamine and stepdown latency in mice. Psychonomic Science, 1972, 26, 39-40.

Carlton, P. Brain-acetylcholine and inhibition. In J. T. Tapp (Ed.), Reinforcement and behavior. New York: Academic Press, 1969.

Chiappetta, L., \& JaRvik, M. E. Comparison of learning impairment and activity depression produced by two doses of cholinergic blocking agents. Archives Internationales de Pharmacodynamie et de Therapie, 1969, 179, 161-166.

Curtis, D. R., \& Crawford, J. M. Central synaptic transmission-microelectrophoretic studies. Annual Review of Pharmacology, 1969, 9, 209-240.

Dilts, S. L., \& BerRY, C. A. Effects of cholinergic drugs on passive avoidance in the mouse. Journal of Pharmacology and Experimental Therapeutics, 1967, 158, 279-285.

Domino, E. F. Role of the central cholinergic system in wakefulness, fast wave sleep and no-go behavior. In The present status of psychotropic drugs. Proceedings of the $V I$ International Congress of the C.I.N.P. Excerpta Medica International Congress, 1968.

Domino, E. F., \& Yамамото, K. Nicotine: Effect on the sleep cycle of the cat. Science, 1965, 150, 637-638.

Glick, S. D., \& Greenstein, S. Differential effects of scopolamine and mecamylamine on passive avoidance behavior. Life Sciences, 1972, 11, 169-179.

Goldberg, M. E., Sledge, K., Hefner, M., \& Rabichaud, R. C. Learning impairment after three classes of agents which modify cholinergic function. Archives Internationales de Pharmacodynamie et de Therapie, 1971, 193, 226-235.

Kawamura, E. F., \& Domino, E. F. Differential actions of $m$ and $n$ cholinergic agonists on the brain stem activating system. International Journal of Neuropharmacology, $1969,8,105-115$.

KsIR, C. J. Scopolamine effects on two-tailed delayed-response performance in the rat. Psychopharmacologia, 1974, 34, 127-134.

LAties, V. G., \& WEIss, B. Influence of drugs on behavior controlled by internal and external stimuli. Journal of Pharmacology and Experimental Therapeutics, 1966, 152, 388-396.

Meyer, M. E., Severson, G. A., \& Thompson, R. W. Scopolamine, methylscopolamine, and response conditioned inhibition in rats. Physiological Psychology, 1976, 4, 43-44.

Meyers, B., Roberts, K. H., Riciputi, R. H., \& Domino, E. F. Some effects of muscarinic blocking drugs on behavior and electro-cardiogram. Psychopharmacologia, 1964, 5, 289-300.

Oliverio, A. Effects on mecamylamine on avoidance conditioning and maze learning of mice. Journal of Pharmacology and Experimental Therapeutics, 1966, 154. 350-356.

Oliverio, A. Contrasting effects of scopolamine on mice trained simultaneously with two different schedules of avoidance conditioning. Psychopharmacologia, 1967, 11, 39-51.

Pert, A. A., \& Avis, H. H. Dissociation between scopolamine and mecamylamine during fear conditioning in rats. Physiological Psychology, 1974, 2, 111-116.

SChechter, M. D., \& Rosecranz, J. A. Behavioral evidence for two types of cholinergic receptors in the CNS. European Journal of Pharmacology, 1971, 15, 375-378.

Schechter, M. D., \& Rosecranz, J. A. CNS effect of nicotine as the discriminative stimulus for the rat in a T-maze. Life Sciences, 1976, 10, 821-832.

STEIN, L., \& SeIfTer, J. Muscarinic synapses in the hypothalamus. American Journal of Physiology, 1962, 202, 751 .

Suits, E., \& IsaAcson, R. L. The effects of scopolamine hydrobromide on one-way and two-way avoidance learning in rats. International Journal of Neuropharmacology, 1968, 7, 441-446.

(Received for publication October 18, 1976.) 